\title{
Access Denied? The Use of Manuscript Material
}

\section{Introduction}

\author{
CLYDE C. WALTON
}

\author{
Director, Northern Illinois University Libraries \\ Chairman, Manuscripts Committee \\ of the Rare Books \& Manuscripts Section
}

On June 25, 1973, at the Las Vegas Conference, the Manuscripts Committee of the Rare Books and Manuscripts Section of the Association of College and Research Libraries sponsored the first in a series of programs which will deal with problems concerning manuscript collections and their use. The first program was titled "Access Denied? The Use of Manuscript Material Assembled to Support the Publication of 'The Collected Works of. ...'" The topic was explored by three scholars: Dr. Herman Kahn, assistant director for manuscripts and archives, Yale University; Dr. William S. McFeely, professor of history, Mt. Holyoke College, South Hadley, Massachusetts; Dr. John Y. Simon, executive director, Ulysses S. Grant Association and editor, The Papers of Ulysses S. Grant, Southern Illinois University, Carbondale, Illinois.

Unfortunately, space limitations make it impossible to publish all three papers. Nevertheless, the basic issues are fully developed in the two papers we are able to present here, with Dr. McFeely speaking for "open access" and Dr. Simon pointing out the problems involved in "open access."

The Manuscripts Committee welcomes whatever comments members may care to make.

Please direct them to the chairman. 